\title{
СОЦИАЛЬНАЯ ОНТОЛОГИЯ В КОНТЕКСТЕ РАЗРАБОТКИ СОВРЕМЕННОЙ СОЦИАЛЬНОЙ ТЕОРИИ
}

\section{В.И. Палагута}

Около двадцати лет назад известный американский футуролог и историк Фрэнсис Фукуяма в своей статье, принесшей ему известность, «Конец истории?» [5], наравне с прогнозом будущего развития человеческой цивилизации, обозначил и качественно новый, «аисторический», подход в изучении современных социальных реалий. В то же самое время английский социальный географ Эдвард Соуджей создает свой бестселлер «Постмодернистская география. Реабилитация пространства в критической социальной теории» [8]. Примечательно, что ключевым положением обеих работ стало обоснование кардинального разрыва с идеей историзма в понимании реалий современного социального мира. Более того, и американский футуролог, и английский социальный географ фактически констатировали отход социально-гуманитарных наук от идеи темпоральности как базового онтологического и методологического принципа в изучении социальной реальности и социума в целом и зафиксировали тенденцию в направлении пространственной переориентации опыта современного субъекта.

Иначе говоря, данное положение ознаменовало не только распространение иного основополагающего принципа в изучении феномена социального, но и обозначил повсеместное применение иной аналитики субъективности, опирающейся на пространственно-картографическое, топографическое представление реальности. Безусловно, данная концептуализация реальности не нова, она разрабатывалась учеными различных направлений социально-гуманитарного знания, прежде все-

Актуальні проблеми духовності: 
го, представителями социологии знания и социальной и культурной антропологии (в частности, А.Лефевром и М.де Серто), а также различными направлениями постмодернистской философии, выдвинувшими принципы подобной концептуализации во второй половине прошлого столетия. Но именно два десятилетия назад, на наш взгляд, пространственная концептуализация получила статус базового универсального объяснительного принципа в интерпретации социальной реальности в социально-гуманитарных науках, а работы упомянутых нами ученых стали своего рода «знаковыми» при переходе к новой парадигме в социогуманитарном познании.

Данная тенденция «опространствливания» реальности интерферируется с другой тенденцией в развитии современной философии, обозначившейся еще в начале прошлого века, - с так называемым «лингвистическим поворотом», утвердившим язык как одну из приоритетных сфер философского исследования и затронувшим в той или иной мере практически все социально-гуманитарные науки. Так, по мнению одного из ведущих современньх немецких философов К.-О.Аппеля, история западной философии имеет три этапа своего становления: онтологический - от Платона до Р. Декарта, эпистемологический - от Р. Декарта до И.Канта и лингвистический-от Л. Витгенштейна и $\Phi$. Соссюра до Ж.Лакана [7]. Последний этап и в начале нынешнего века не только не прервался, но и интенсивно развертывается как в философских, так и в междисциплинарных социогуманитарных исследованиях.

В контексте обозначенных выше тенденций, нынешнее состояние развития социальной философии характеризуется постановкой и разработкой ряда современных концептуальных положений, совмещающих исследование социальной реальности с изучением феномена субъективности, и, в конечном счете, способствующих разработке современной социальной теории. Речь здесь, на наш взгляд, идет о ряде следующих ключевых положений. Так, в социальной теории давно уже прослеживается кризис субстанционалистской парадигмы социума, выдвинутой еще на заре Нового времени, прежде всего, социально-философскими трудами Т. Гоббса и философов-утопистов, рассматривавших социум как социальное тело, а в дальнейшем разрабатывавшейся представителями классической социологии - М. Вебером, Г. Зиммелем, Т. Парсонсом, П.Сорокиным, Ф.Теннисом. В рамках классической социальной теории социальный порядок является фундаментальной характеристикой и условием любого общества и представляется стабильно установленной, самоочевидной, охватывающей 
без остатка все социальное пространство и постоянно воспроизводимой в историческом времени константой. Кризис классической социальной теории в последнее время во многом связан как с радикальными изменениями в структуре и динамике современных обществ, так и с принятием и критическим усвоением научным сообществом основных положений постмодернизма. Известно, что постмодернисты отвергают устоявшееся представление о социуме как определенной целостности и упорядоченности, задающей субъекта внешним образом через процессы социализации, социальной интериоризации и интроекции. Социально-философские построения постмодернистов, и особенно Ж. Делеза и Ф. Гваттари, Ж. Бодрийяра и Ж.-Ф. Лиотара наглядно продемонстрировали предел применимости к анализу социума субстанционалистской парадигмы.

Как альтернатива субстанционализму постмодернизмом была предложена концепция социального устройства через множественность локальных, сингулярных порядков, задающих релятивность и изменчивость социального, и осуществляемого посредством множества субъективных практик, имеющих дискурсивно-речевую основу. Но подобная концепция в предельном смысловом выражении низводит социальное к хаотически случайному, атомарному, стохастическому, что подвергает сомнению саму идею социального порядка как регулятивной основы социума.

При рассуждении с позиций доминировавшего в последнее время в социальной теории структурно-функционального подхода, манифестирующего социальный порядок и целостность как неотъемлемые атрибуты социума, возникает другая проблема- «исчезновение» субъекта из поля социальной теории - его или нет изначально вообще, или он «пристегивается» задним числом к социуму. Тогда весьма уместным и справедливым будет замечание по поводу классической социальной теории Р. Дарендорфа: «Человека, которого изучают социологи ... на самом деле не существует» (цит. по: [4, с. 30]). Более того, последние исследования в области социально-гуманитарных наук все настойчивее проводят идею, что редукция субъекта к социальной системе блокирует адекватное понимание процессов, протекающих в самом социуме.

Если же априорно в качестве онтологических условий социума не задавать целостность и упорядоченность социальной реальности (а это главные характеристики функционализма в изучении социума), тогда может произойти своего рода вытеснение самого социального за границы теоретического дискурса, когда такое вытеснение редуцирует социальное к множеству сингулярных дискурсивных порядков. Здесь 
возникает дилемма: либо социальное как таковое «распыляется», «растворяется» в партикуляризме, либо необходимо признать социальную легитимность вариабельности и сингулярности, их социальную ангажированность как таковую. Или, наоборот, сохранять понимание социального как целостности и упорядоченности. [...] Но тогда проблема как таковая упраздняется, и мы в качестве ее разрешения получим модернизированный вариант субстанционализма.

Тем самым, необходимо признать, что концептуализация сингулярного в рамках онтологии классической социальной парадигмы невозможна, поскольку учет субъективной сингулярности предполагает учет каждой отдельной сингулярности. Но это означает, что необходимо или разработать столько социальных теорий, сколько существует сингулярностей, или - в идеальном случае - попытаться разработать новую универсальную теорию, учитывающую каждую сингулярность, т. е. теорию на совершенно иных онтологических и методологических основаниях. Но возможно ли это в принципе? А если возможно, то какой вид примет данная теория?

Таким образом, если не довольствоваться традиционным решением и признать социальную легитимность за партикулярностью, тогда необходимо констатировать, что проблема имеет два аспекта в своем решении, а именно: изучение социального с позиций субъекта, а не наоборот, и исследование механизмов вхождения субъективности в пространства социального. И в этом смысле нельзя не признать правоту постмодернизма в актуальности постановки проблемы.

Эта проблематичность феномена социального отчетливо осознавалась классиком социологии Э. Дюркгеймом, в своих работах постоянно обращавшегося к изучению природы социального и во многом предопределившего разработки современной социальной онтологии. В самом деле, в своих трудах Э. Дюркгейм, исследуя феномен социального, проводил различение самих «социальных фактов»в виде обычаев, верований, преданий и т. д., способных к самокопированию, к самовоспроизведению, и субъективно-ценностных суждений о них со стороны субъекта как деятеля определенного социума. Причем первые производились и воспроизводились посредством коллективных представлений и носили для субъекта обязательный, даже принудительный характер (т. е. воспринимались им как непререкаемая данность). Так, существуя независимо от представлений конкретных субъектов и являясь своего рода «социальной вещью», причину появления того или иного социального факта, согласно французскому ученому, следует искать среди предшествующих социальных фактов, а не в состояниях представле- 
ний субъектов, что позволяет изучать их научным образом, проводя различие между ценностными и «реальными» суждениями [1, с. 31-39, $51,126,286-304]$.

С другой стороны, и в этом очевидный парадокс теории Э. Дюркгейма, не оцененной по достоинству его современниками, ценностные суждения в виде мнений, идеалов, ожиданий, чаяний и т. д., осознаются субъектами, «ухватываются» ими, будучи маркированными как «социальные вещи». Соответственно, объективно присущие «социальной вещи» черты могут ошибочно казаться первопричиной той «ценности», того значения, которое этим «вещам» приписывается со стороны субъекта. От такого ложного понимания постоянно предостерегал французский социолог. Так, в «Элементарньх формах религиозной жизни» Э.Дюркгейм особо подчеркивал, что «мы никогда не можем избежать дуализма нашей природы и полностью освободиться от физической необходимости: чтобы выразить самим себе наши собственные идеи; необходимо..., чтобы мы их привязали к определенным вещам, которые их символизируют. .. Объект, служащий опорой идеи, есть нечто несущественное в сравнении с идеальной суперструктурой, за которой она исчезает, и таким образом в суперструктуре сам по себе объект есть ничто» [2, с. 470] (курсив мой- В. П.). В этом парадоксе видел французский социальный теоретик разгадку феномена социального: «Не следует называть это бредом, такая объективация идей основывается не на природе материальных вещей, в которые они себя размещают, но на природе общества» [2, с. 470] - резюмирует свою позицию ученый.

Тем самым, социум с его структурами и установлениями изначально позиционируется в представлении ее членов как священное образование. На первый взгляд, Э.Дюркгейм вроде бы обозначил разделяемую представителями классической социологии схему включенности субъекта через процессы социализации в социальное пространство, где примат последнего очевиден. Но это только на первый взгляд. Здесь прорисовывается более сложная схематика их комплементарности, включающая наравне со священными «социальными вещами» и область представлений как их социального хранилища, и область субъективной символизации обычных материальных предметов, что наводит на мысль, что субъекту отведена далеко не последняя роль в их взаимодействии. Так или иначе, но область представлений, будь они даже и коллективными, позволяют сделать ряд весьма существенных выводов.

Во-первых, можно отметить коллизию между исходной позитивис- 
тской направленностью самой социологии как знания, ориентированного на поиск и конструирование объективированных скрытых связей социума, и попыткой Э. Дюркгейма «ухватить» генерирующие механизмы, производящие субъекта в социуме. Но научные процедуры объективации и структурирования, как известно, всегда имеют рефлексивный характер. Они пытаются воссоздать уже свершившееся с помощью предельно общих, универсальных понятий, подводящих под критерий всеобщего множество объектов (в нашем случае, в качестве объектов выступает совокупность субъектов), оставляя при этом вне рассмотрения уникальные, неповторимые, особенные характеристики, участвующие в механизмах порождения субъекта в самом генеративном акте или процессе.

Эта «ловушка» классической социологии хорошо осознавались Э. Дюркгеймом. С одной стороны, для социолога Э. Дюркгейма, поскольку он социолог и позитивист по определению, присуще стремление выявить основополагающие характеристики и факторы социума, теоретически реконструировав структуру общества в целом или важнейшие его составляющие по уже накатанной схеме (достаточно хотя бы внимательно прочитать его «Метод социологии»). Вместе с тем французский ученый прекрасно осознавал, что социум состоит из субъектов, а их мир невозможно понять, лишь объективируя и структурируя многообразие «социальных вещей», с которыми взаимодействует субъект. Чтобы реально что-то узреть в «социальной вещи», необходимо «подставить» себя как субъекта под ее воздействие и этим «попасть» в пространство его создания или воссоздания. Тем самым необходимо познать воздействие социального как совокупности специфически субъективньх актов, которые удерживают социум в положении социума, а это уже иная онтология - онтология изучения порождающих или генерирующих механизмов социального. Но тогда, прежде всего, необходимо отказаться от позиции абсолютного наблюдателя в социальной теории, с ее универсальными процедурами объективации и структурирования. Социальный исследователь должен быть как психоаналитик - и теоретиком, и практиком одновременно.

Во-вторых, обращение французского ученого к изучению архаических обществ и их верований выявило одну интересную особенность. А именно, - для коллективных представлений древности существовала нерасчлененность внешнего и внутреннего, плана действия и плана сознания/бессознательного, где внешне выраженное действие автоматически преобразовывалось во внутренний план субъекта. Вот где содержится «ключ» к исследованиям феномена социального у 
Э. Дюркгейма. Напротив, для современного опыта субъективности все гораздо сложнее. Такого органичного, «плавного» перехода не существует, о чем достаточно красноречиво и, надо сказать, по делу высказывались постмодернисты. У современного субъекта существует разрыв внешнего и внутреннего, а его преобразование возможно только в случае актуализации «внутреннего опыта» через трансгрессию (термин Ж. Батая), использующего символические модели конструирования социального мира, а это уже качественно новый уровень опыта субъективности. Вот почему недопонимание этого момента порождает одно из существенных современных заблуждений социального бихевиоризма, что, основываясь на знании социальной теории, можно только лишь внешними, т. е. структурными преобразованиями изменить социум.

К слову сказать, внутренне-символическое конструирование реальности современным субъектом не анализировалось Э. Дюркгеймом специально, но он достаточно четко обозначил разрыв и рассогласование внутреннего представления с внешней материально-физической действительностью: «Это верно, что индивидуальные представления также вызывают в организме реакции, с которыми нельзя не считаться. Однако эти представления можно помыслить и отдельно от тех физических процессов, которые они сопровождают или за которыми следуют, но которые они не конституируют» [2, с.439].

Краткий экскурс в социально-антропологическую проблематику Э. Дюркгейма позволяет нам сделать вывод, что французский социолог, обозначил одну из современных проблем социогуманитарных исследований - отказ от субстанционализма как базового принципа и непринятие в «чистом» виде его альтернативы - релятивизма. Э. Дюркгейм контурно очертил возможные варианты решения названной проблмы в виде поиска определенных антропологических констант и универсальных символических образований.

И в этом смысле весьма плодотворной является идея внутреннего символического конструирования феномена социального. Необходимо отметить, что эта идея указывает на возможность разработки онтологических оснований современной социальной теории, но уже с позиций субъектно-ориентированного подхода. На это сейчас направлены усилия ряда социальных теоретиков, стремящихся в изучении социальной реальности перейти с позиций позитивизма и субстанционализма на позиции принципиально других теоретических подходов, в частности к социально-топологическому и социально-конструктивистскому подходу. 
Так, в качестве решения проблемы представления субъекта в структурах социального пространства П. Бурдьё и его школой был предложен социально-топологический подход. Он позволяет рассматривать социальную реальность через множество локальных, партикулярных социальных порядков, представляющих собой на уровне социума динамически связную структуру пространства социальных топосов. Российский социолог Н. Шматко, давая разъяснения смысла этого ключевого положения социальной топологии, отмечает, что «топос формируется взаимной близостью (сходством) социальных феноменов, образующих пучок причинно-следственных рядов. Это означает, что социальные явления, принадлежащие данному топосу, должны формировать необратимую во времени последовательность событий» [6, с. 15]. Добавим, что из данной необратимой последовательности событий субъекту «выскочить» практически невозможно.

Вместе с тем, социальный порядок определяется подвижностью, релятивностью, «текучестью» (термин З.Баумана) всего комплекса социальных топосов, определяющих, в конечном счете, всю диспозицию социальных отношений и позиций, занимаемых субъектом в тот или иной момент времени в социальном пространстве. Но социальная топология составляет макросоциальный уровень существования социума и субъекта. Упомянутые же ранее порождающие механизмы социального существуют и генерируют субъективность исключительно на микросоциальном уровне существования социума. Он ненагляден, ненаблюдаем, своего рода «метафизичен», но его существование имеет свои последствия в макросоциуме - в социальном пространстве интерсубъективных отношений и позиций. Поэтому макроуровень анализа социума должен быть дополнен анализом множества микросоциумов, которые включают субъектов как неотъемлемый фактор генерирования социальности. Характерной особенностью социальной позиции субъекта на микроуровне социальности является рассмотрение пространств социальных топосов как специфических пространств говорения, т. е. рассмотрение субъективности сквозь призму дискурсивных практик, являющихся по своей сути символико-знаковыми образованиями.

В заключение настоящей статьи необходимо остановиться на еще одном аспекте проблемы. Исследование механизмов «вхождения» субъекта в пространства социального переплетается с одним из ключевых вопросов современной социальной философии - «возвращения» субъекта в поле ее исследования. Как уже говорилось ранее, необходимость его решения определяется очевидным кризисом объективист- 
ских подходов в социально-гуманитарных науках - функционализма в социологии, бихевиоризма и теории потребностей в психологии, биологизма в теоретическом психоанализе, теории социальных общностей в социальной психологии. Поэтому сама необходимость в философском понятии «субъект» вполне очевидна и не вызывает сомнения. Она во многом определяется универсальностью связанной с этим понятием проблематикой и является своего рода точкой отсчета для философской рефлексии.

Кроме того, понятие субъекта по своей сути является полисемантичным, поскольку не существует общепринятого подхода к трактовке этого понятия в социально-гуманитарной литературе. Его значение определяется исключительно контекстом, который задается проблемным полем того или иного исследования. В зависимости от решаемых исследовательских задач под понятие «субъект» обычно подводится то или иное конкретное, «прагматическое» основание. Поэтому данное определение субъективности сейчас может быть каким угодно. Оно может быть ориентировано на различные социально-гуманитарные науки - лингвистику, социологию, политологию, психологию и другие. Кроме того, категория «субъект» изначально «нагружено» смысловыми коннотациями «родственных» ей понятий - «человек», «индивид», «личность», «самость», а в последнее время в социальных науках получают распространение понятия, замещающие категорию субъект такими как «актор», «социальный агент» и другие. Вместе с тем, по нашему убеждению, разнообразное содержание, которым наполняется данная категория в социогуманитарных науках, является вторичным в отношении к его первичному - онтологическому значению.

Но каково же тогда онтологическое значение категории «субъект»? О том, что этот вопрос будоражит умы современных исследователей, сомневаться не приходится. Здесь достаточно сослаться на одного из известнейших мыслителей современности, руководителя словенской школы теоретического психоанализа, С. Жижека. Так, анализируя значение категории «субъект» в свете современной виртуализации социума, словенский ученый отстаивает идею, что сегодня мы присутствуем при возрождении картезианского субъекта. По мысли С. Жижека, возникновение виртуальных сообществ порождает такую ситуацию, в которой каждый может выбрать и конструировать субстанциональные характеристики собственной идентичности (такие как paca, национальность, пол, сексуальная ориентация и т. д.). «Я хочу сказать, что все ваши физические свойства заменяемы, а вот неизменным в субъекте остается именно cogito ergo sum, то есть картезиан- 
ский субъект. Я считаю, что только там, в виртуальном сообществе достигаем мы уровня картезианской субъективности; мы не только не вышли за ее пределы, но еще только приближаемся к ней» [3, с. 171], резюмирует свою идею С. Жижек. Тем самым, виртуальные сообщества указывают на проблему онтологических оснований современного субъекта, которые лишены субстанционального содержания. Тогда получается парадоксальная ситуация: онтология субъекта есть (ее не может не быть), но у нее нет субстанции как таковой. Но какова эта онтология и как она взаимосвязана с социальной онтологией, с микроуровнем и макроуровнем социального, как она конструируется, чем определяется и какие характеристики предусматривает - все это требует дальнейшего изучения. Тем более что без исследования онтологии субъекта на новом уровне невозможна разработка современной социальной теории.

\section{1 Литература}

[1] Дюржгейм Э. Социология. Ее предмет, метод, предназначение. М.: Канон, 1995.

[2] Дюркгейм Э. Элементарные формы религиозной жизни (фрагменты) // Религия и общество. Хрестоматия по социологии религии. - М.: Аспект Пресс, 1996. - С. 438-470.

[3] Жижек C. Власть и цинизм // Кабинет: Картины мира 1. - СПб.: Инапресс, 1998. - С. 162-175.

[4] Цит. по: Монсон П. Лодка на аллеях парка: введение в социологию // Социологические исследования. - 1996. - № 5. - С. 24-35.

[5] Фукуяма Ф. Конец истории? // Вопросы философии.-1990.№3. - C. 134-148.

[6] Шматко Н. Плюрализация социального порядка и социальная топология // Социологические исследования. - 2001. - № 9. - С. 1418.

[7] Apel K.-O. Communication and the foundations of the humanities // Acta sociologica. - 1972. - Vol. 15 - № 1. - P. 26-44.

[8] Soja E.W. Postmodern Geographies. The Reassertion of Space in Critical Social Theory - London, New York: Verso, 1989. 